\section{Migration of embolization coils placed to stop a severe iatrogenic bleed following endoscopic ultrasound-guided cystogastrostomy}
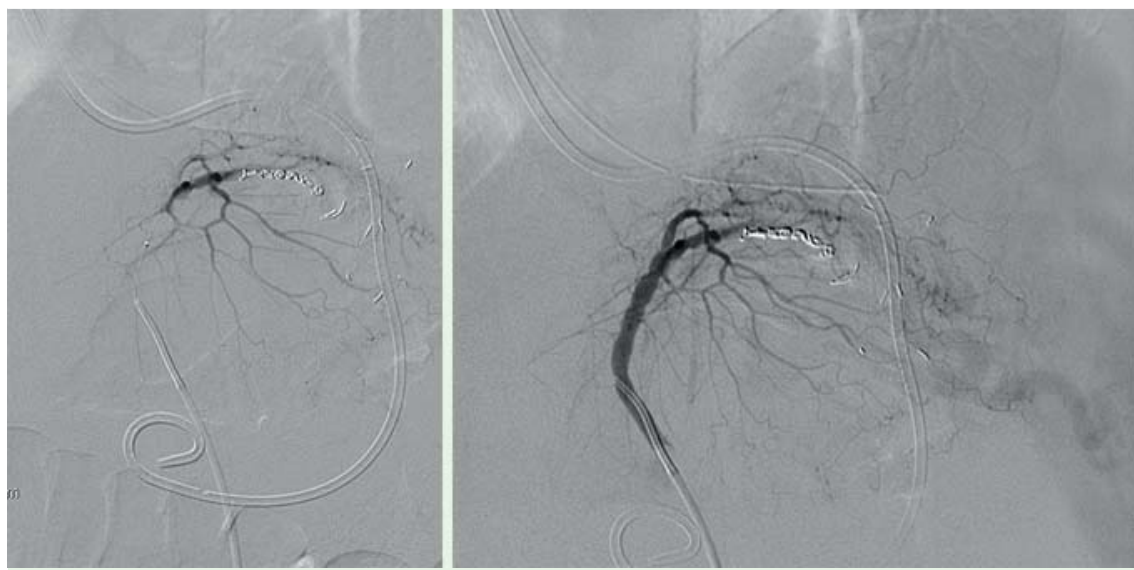

Fig. 1 Transcatheter arterial embolization (TAE) with metal coils being performed by the radiology service in a patient who experienced severe bleeding after endoscopic ultrasound (EUS)-guided cystogastrostomy.
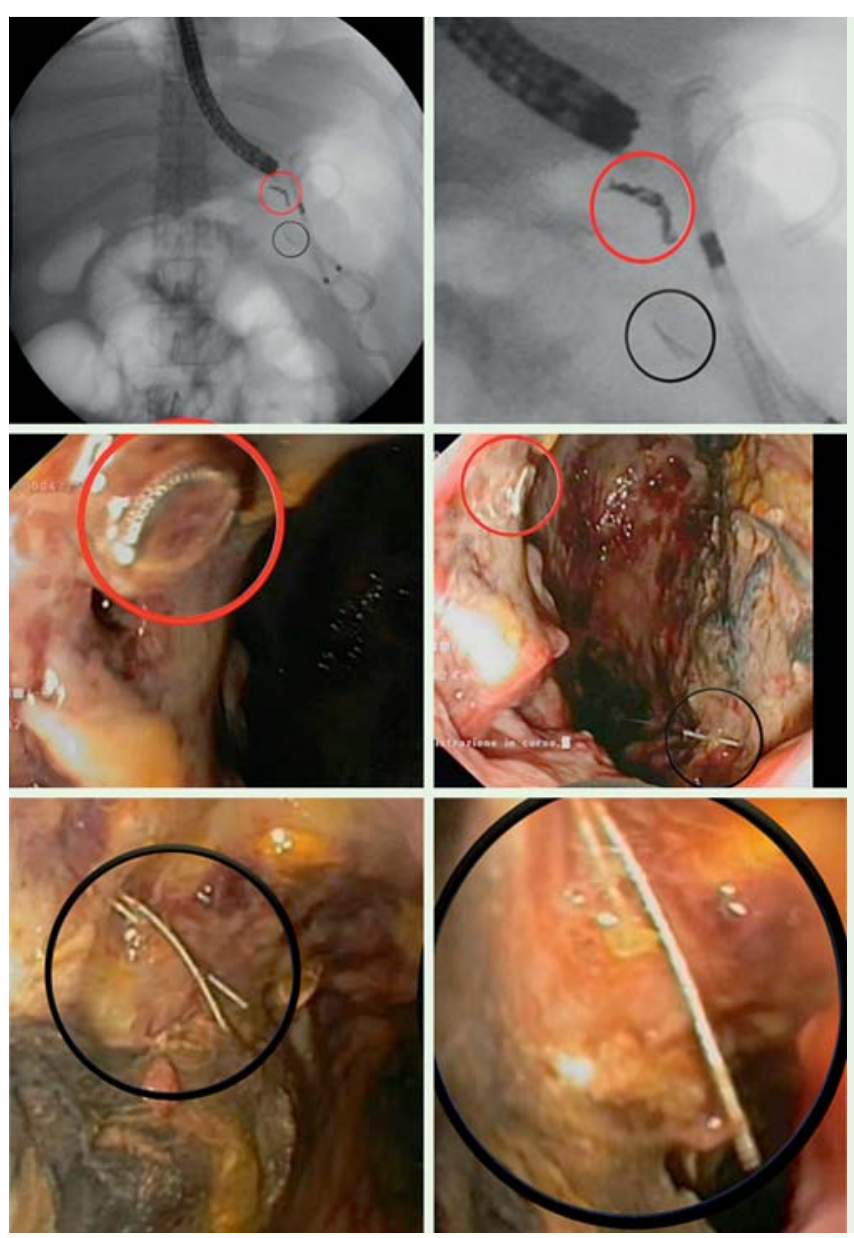

A 32-year-old man with a large symptomatic pseudocyst was referred for endoscopic ultrasound (EUS)-guided cystogastrostomy. The procedure was complicated by an iatrogenic bleed from the pseudocyst border, which was associated with hypovolemia and a significant drop in hemoglobin.

A fully covered self-expandable metal stent (SEMS) inserted between the stomach and the pseudocyst did not stop the bleeding. As a result, transcatheter arterial embolization (TAE) with metal coils was performed by our radiology service (๑ Fig.1). Hemostasis was achieved immediately after TAE.

After 5 days the patient developed fever and pain. A gastroscope was used to inspect the interior of the pseudocyst cavity, and the metal stent was replaced by two pigtail stents. Large blood clots and necrotic material observed in the cyst were removed with a Roth net. During this procedure, two of the metal coils used during TAE were seen on the border of the cyst at the site of the bleeding; however, two other coils appeared to have migrated directly from the vessel into the pseudocyst cavity ( $\bullet$ Fig. 2 ). After the procedure, no further evidence of hemorrhage was recorded. Endoscopic pseudocyst lavage was repeated 4 days later, and the patient was discharged home 2 weeks later.

Embolization of selected arteries with metal coils has been previously used to manage iatrogenic EUS-guided cystogastrostomy bleeds [1]. Migration of the coils from the embolized vessels into the gastrointestinal tract is extremely uncommon, with only one documented case of migration of a steel-wire coil into the stomach after arterial embolization [2]. No reports of the migration of metal coils into a pancreatic pseudocyst have been previously reported. TAE appears to be a minimally invasive, highly effective treatment in patients who hemorrhage after cystogastrostomy.

Endoscopy_UCTN_Code_CPL_1AH_2AC

Competing interests: None 
Antonino Granata', Gabriele Curcio', Neville Azzopardi ${ }^{1}$, Ilaria Tarantino ${ }^{1}$, Luca Barresi ${ }^{1}$, Roberto Miraglia ${ }^{2}$, Mario Traina ${ }^{1}$

${ }^{1}$ Endoscopy Service, Department of Diagnostic and Therapeutic Services, Mediterranean Institute for Transplantation and Advanced Specialized Therapies (ISMETT), Palermo, Italy

2 Radiology Service, Department of Diagnostic and Therapeutic Services, Mediterranean Institute for Transplantation and Advanced Specialized Therapies (ISMETT), Palermo, Italy

\section{References}

1 Brandon JL, Ruden NM, Turba UC et al. Angiographic embolization of arterial haemorrhage following endoscopic US-guided cystgastrostomy for pancreatic pseudocyst drainage. Diagn Interv Radiol 2008; 14: 57-60

2 Takahashi T, Shimada K, Kobayashi $N$ et al. Migration of steel-wire coils into the stomach after transcatheter arterial embolization for a bleeding splenic artery pseudoaneurysm: report of a case. Surg Today 2001; 31: $458-462$
Bibliography

DOI http://dx.doi.org/

10.1055/s-0034-1377212

Endoscopy 2014; 46: E306-E307

(C) Georg Thieme Verlag KG

Stuttgart · New York

ISSN 0013-726X

Corresponding author

Antonino Granata, MD

Endoscopy Service

ISMETT

Via Tricomi 5

90127 Palermo

Italy

Fax: +39-091-2192400 (specify Endoscopy Service) agranata@ismett.edu 